\title{
Palestinian doctors' views on patient-centered care in hospitals
}

Wasim I M Sultan ${ }^{1 *}$, Mutaz I M Sultan² and José Crispim³

\begin{abstract}
Background: Understanding the perceived importance of Patient-Centered Care (PCC) among Palestinian doctors and how the provider and other clinical characteristics may impact their views on PCC is essential to determine the extent to which PCC can be implemented. This study investigates the provision of PCC among hospital doctors in a developing and unstable country, namely, Palestine.

Methods: This descriptive, cross-sectional research employed self-report survey among 369 Palestinian doctors working in hospitals in 2016. Respondents completed the Provider-Patient Relationship Questionnaire (PPRQ) and were asked to rate the importance of 16 PCC subjects in a context-free manner. Then they scored the existence of eight contextual attributes in their workplace.
\end{abstract}

Results: Although $71.4 \%$ of the participants got training in communication, only $45 \%$ of the participants knew about PCC. $48.8 \%$ of doctors considered the "exchange of information" with patients most important PCC component. Clustering identified three groups of doctors: $32.4 \%$ of doctors reported good perceptions of PCC, $47.5 \%$ moderate; and $20.1 \%$ poor. Older, married, and specialist doctors and those familiar with PCC are more likely classified in the "good" cluster. Results revealed a significant difference between doctors' views based on their gender, experience, marital status, previous knowledge about PCC, and type of hospital in favor of males, experienced, married, familiar with PCC, and doctors in private hospital respectively. The level of job interest, nurses' cooperation, the tendency of patients to hide information, and doctor's friendly style were positively related with more perceived importance of PCC.

Conclusion: We identified benchmark doctors who perceive the high relative importance of PCC. Our results highlighted knowledge gaps and training weaknesses among doctors in public and private hospitals in respect to their views on PCC. Decision makers may invest in the determined contextual predictors to enhance attitudes towards PCC. This work doesn't address patients' views on PCC.

Keywords: Doctor-patient relationship, PCC, Doctors' views, Palestinian hospitals

\section{Background}

There is ample evidence to support that implementing Patient-Centered Care (PCC) enhances health outcomes in different ways: improved patient satisfaction, enhanced behavior change, building trust, improving patient adherence, better providers' clinical accuracy, and more active patient self-management [1-13]. From an economic perspective, gains through fewer diagnostic tests, fewer referrals, and less cost of nonadherence also can be achieved when implementing PCC $[14,15]$.

\footnotetext{
* Correspondence: waseem@ppu.edu

${ }^{1}$ School of Administrative Sciences, PPU-Palestine \& NIPE-Portugal, Hebron, Palestine

Full list of author information is available at the end of the article
}

PCC is well documented as a key attribute of highquality healthcare services $[10,16]$. The Institute of Medicine considered the PCC as one of the six essentials of the quality of care in the twenty-first century $[8,17]$. The PCC approach emphasizes the effective provider-patient relationship and addresses better understanding of patient's own feelings, preferences, and views about the disease and treatment [18]. The fundamental characteristics of PCC, as identified in the literature, are the patient involvement in care and the individualization of patient care [14].

From a clinical practice perspective (applied in this research project), PCC refers to providing a providerpatient relationship that integrates the well-being of the individual and the psychosocial context of patients [19].

(c) The Author(s). 2018 Open Access This article is distributed under the terms of the Creative Commons Attribution 4.0 International License (http://creativecommons.org/licenses/by/4.0/), which permits unrestricted use, distribution, and 
The psychosocial aspects of care (the patient's values, emotions, needs, expectations, and preferences) are considered to guide clinical decisions [17]. A common understanding of the patient's condition will help the provider getting the relevant information and execute the best possible clinical strategy [11]. Therefore, patients are more likely to receive the maximum achievable benefits $[20,21]$.

To date, no studies have examined the Palestinian doctors' views on the provision of $\mathrm{PCC}$, therefore, our work addresses a major gap in the literature by empirically investigating the perceived importance of PCC among doctors in a developing and unstable country, namely, Palestine. Previous studies are limited to describe the health reform initiatives in Palestine $[22,23]$ or to describe the status of healthcare [24-30]. To elaborate further on the challenges of implementing PCC, we examine the associations between doctors' views and contextual factors (structural attributes in the workplace). Therefore, our work has the potential to determine the extent to which PCC can be implemented in the Palestinian context and help to capture the areas that merit collaborative institutional efforts for enhancing the PCC knowledge and practice.

To sum up, because PCC is an essential attribute of the high-quality healthcare system, and because the provider-patient relationship is an area of significant concerns in the East Mediterranean Region [31], our intention is to address two major research objectives:

(1) Assess the perceived importance of implementing PCC among the Palestinian doctors in hospitals.

(2) Explore provider and other clinical characteristics that may have an association with doctors' views on PCC.

\section{The case of Palestine}

Behind the daily life of the Palestinians lies an exceptional set of factors that drives their behaviors and contributes to their performance. Palestinians are stressed by an environment characterized by chronic conflict with the Israelis, worsening economic conditions, restrictions on movement, and the gap between the reality of occupation and the yet to be the State of Palestine [32-34]. While acting in a stressful environment, Palestinian hospital doctors are challenged to cope with professional practices. Therefore, understanding their views on the importance of delivering PCC serves the needs to determine the extent to which PCC can be implemented.

The Palestinian health care system is politically framed to serve previous commitments and liberation promises of the public authorities rather than being socioeconomically structured [35]. For example, although public hospitals suffer from understaffing, shortages of supplies and high rates of bed occupancy [27], the applied health insurance schemes cover most of the population and increase the burden on the limited public services [29]. Therefore, it is believed that the emphasis on quantity preceded the quality of care in the Palestinian hospitals [26].

Perhaps gauging the growing problems in the public hospitals, the Palestinian Ministry of Health ( $\mathrm{MoH})$ allocates more than $35 \%$ of its budget to purchase hospital services from the private hospitals [36]. While the decision seems to have had a favorable impact on better access, quality is compromised. The $\mathrm{MoH}$ is loaded with receivables they can't reimburse for the private hospitals, as a result, the private hospitals suffer financial deficit to meet salary payments on a regular basis and their employees (including doctors) are less induced to do any more than what is minimally required. This complex context may affect doctors' views on PCC $[16,37]$. Hence, exploring what are the provider and other clinical characteristics that may contribute to doctors' views on PCC is also an important topic?

\section{The scope of the study}

PCC is a multidimensional concept, regrettably, the literature lacks consensus on a standard list of PCC components [38], but, previous studies tend to focus on components of PCC like the patient's agenda [39], information, communication, and education [7, 17], or shared decision making [40].

The scope of our work is examining the perceived importance of sixteen PCC actions during the medical interview among doctors in Palestinian hospitals. These actions represent four PCC components. Then, to examine the association between the perceived importance of these components and eight contextual factors. The PCC components are: (1) Exchange of information such as listening to the patient, asking questions, giving clear information and using a quiet tone; (2) Individualization such as showing interests in the patient's feelings, wants, expectations, and knowledge; (3) Empathy which represent the doctor's ability to respond to and improve his patient's emotional state [6], evidence shows that doctor's empathy and clinical outcomes are positively related [41]; and (4) Patient involvement such as engaging the patient in informed and shared decision making. To achieve this research objective, we applied the Provider-Patient Relationship Questionnaire (PPRQ) which was developed and tested by Gremigni et al. (2016); a survey that contains 16 scale self-report items [18]. Two recent works have also taken this approach to investigate PCC among healthcare professionals in Italian hospitals [18, 42].

To identify contextual factors that may have effects on the doctors' views on PCC, we reviewed the relevant literature [7, 43-45]. Guided by the literature and building on Epstein and Street work, "Patient-Centered Care is a quality of personal, professional, and organizational relationships ..." [46] we discussed with two doctors an initial 
list of eleven contextual factors. Then, we conducted a pilot survey of ten doctors who confirmed only eight contextual factors and the relevance of PPRQ. These eight contextual subjects capture three sets of potential factors: (1) Organizational factors (structural attributes in the workplace) that include administrative support, workload conditions, and nurses' cooperation [47]. (2) Attributes related to the doctor in the workplace such as job satisfaction, job interest, and his tendency to approach patient's problem either formally or friendly [7, 20, 48-50]. (3) Attributes related to the patient include the level of health literacy and tendency to hide relevant information [51-53]. The doctors are asked to score the prevalence of eight contextual factors.

\section{Methods}

We conducted secondary research to find studies on PCC, health education, communication, or doctor-patient relationship in Palestine. We found few published studies, none of them addressed the provision of PCC. Our research project will answer the following research questions:

RQ1: What is the relative importance of 16 PCC actions (four PCC components) as perceived by the Palestinian doctors?

RQ2: What are the PCC actions or doctor's

background that significantly classify Palestinian

doctors into clusters (like-minded doctors) based on

their views on the importance of PCC?

RQ3: Do Palestinian doctors perceive differently

the importance of PCC components based on their

socio-demographic characteristics or based on the type of hospital they work for?

RQ4: What are the contextual factors related to the perceived importance of PCC components among Palestinian doctors?

\section{Research design}

This descriptive, cross-sectional research used self-report survey among Palestinian doctors working in hospitals. The assessment of attitudes often uses questionnaires and self-report data [54]. Self-report has been identified as a key aspect of medical professionalism [55]. It provides insights into the doctor's thoughts, feelings, and emotions towards the patient-provider relationship [7]. This method is common in the literature to explore doctors' views and professionals in the workplace domains [56-59].

\section{Questionnaire design}

The questionnaire is divided into four sections (see Additional file 1): the socio-demographic characteristics of participants; measures of 16 PCC actions (subjects); measures of eight contextual factors (structural attributes); and four measures of the Socially Desirable Response Set
(SDRS) to test for participants' propensity to give socially desirable answers (adopted from the literature) [60].

The first section includes the sociodemographic characteristics of the participants (Table 1). It is assumed that doctors approach their patients' problems in different ways and according to the doctor's experience levels,

Table 1 Sample characteristics $(N=369)$

\begin{tabular}{|c|c|}
\hline Characteristic & Counts (\%) \\
\hline \multicolumn{2}{|l|}{ Profession } \\
\hline Specialist doctor & $139(37.7)$ \\
\hline Resident doctor & $138(37.4)$ \\
\hline General doctor & $92(24.9)$ \\
\hline \multicolumn{2}{|l|}{ Hospital Department } \\
\hline Surgery & $71(19.2)$ \\
\hline Internal Medicine & $52(14.1)$ \\
\hline Obstetrics \& Gynecology & $34(9.20)$ \\
\hline Pediatrics & $69(18.7)$ \\
\hline Anesthesia & $08(2.20)$ \\
\hline Emergency & $07(1.90)$ \\
\hline Radiology & $14(3.80)$ \\
\hline Other departments & $114(30.9)$ \\
\hline \multicolumn{2}{|l|}{ Gender } \\
\hline Male & $276(74.8)$ \\
\hline Female & $93(25.2)$ \\
\hline \multicolumn{2}{|l|}{ Marital Status } \\
\hline Unmarried & $143(38.8)$ \\
\hline Married & $226(61.20$ \\
\hline \multicolumn{2}{|l|}{ Age } \\
\hline$\leq 35$ years & $222(60.20$ \\
\hline$>35$ years & $147(39.2)$ \\
\hline \multicolumn{2}{|l|}{ Experience } \\
\hline$\leq 5$ years & $218(59.1)$ \\
\hline$>5$ years & $150(40.7)$ \\
\hline \multicolumn{2}{|l|}{ University of Bachelor } \\
\hline Inside Palestine. & $137(37.1)$ \\
\hline Outside Palestine. & $229(62.9)$ \\
\hline \multicolumn{2}{|l|}{ Communication Training } \\
\hline Never got training & $102(27.6)$ \\
\hline Got training & $262(71.4)$ \\
\hline \multicolumn{2}{|l|}{ Knowledge about PCC } \\
\hline Don't know about PCC & $203(55)$ \\
\hline Knows about PCC & $162(45)$ \\
\hline \multicolumn{2}{|l|}{ Hospital settings } \\
\hline Public & $181(49.1)$ \\
\hline Private & $188(50.9)$ \\
\hline Total & $369(100)$ \\
\hline
\end{tabular}


knowledge, background, and beliefs. Therefore, this part describes the sample characteristics and helps to explore differences among doctors based on their characteristics with respect to their views on the relative importance of PCC components.

The second section employs the Provider-Patient Relationship Questionnaire (PPRQ) and includes sixteen subjects of interest that represent four PCC components [18]. We used a five-point Likert scale to score the level of perceived importance and ranging from "not at all important" to "totally important", responses were coded from " 1 " to " 5 " respectively (Table 2). The doctors are asked to report the importance of these actions in a context-free manner.

The third section includes eight factors related to the working place domain (less controlled by the doctor) and related to hospital administration, other professionals (nurses), and the patients. In addition to job interest, job satisfaction, and level of doctor's formal style to communicate with patients.

We used this preliminary version and conducted a pilot study of ten participants. One PCC item was modified to suit the Palestinian social context, and three irrelevant contextual factors were eliminated, in the result, eight contextual factors were analyzed.

The patient-related factors were discussed and confirmed as they may influence the medical interview process [51] for two reasons: First, because it is not uncommon in developing countries that patients hide information about their disease due to perceptions of having social harm in the future; Second, it is assumed that low levels of health literacy in developing countries' setting can impede understanding health information.

\section{Participants}

In 2016, we collected data from doctors working in public and private hospitals in the West Bank and East Jerusalem. We followed a convenient sampling technique. The English printed version of the self-administered questionnaire (Additional file 1) targeted all the full-time hospital employed doctors in the West Bank and East Jerusalem $(N=1418)$. Doctors in psychiatric hospitals were excluded. We obtained ethical approval from the Palestinian Ministry of Health to carry out the research. We started to recruit participants to fill out the questionnaire online, but we failed. Then, using a printed English version of the questionnaire, we asked doctors to participate on a voluntary basis during the 3 days of the National Medical Conference. The conference was organized by the Palestinian Medical Association at the City of Bethlehem in West Bank in October 2016. Doctors were asked to remember recent few medical interviews and how they interacted with their patients, a brief introduction about the research was also explained to each participant. We

Table 2 Descriptive statistics of PCC items and components

\begin{tabular}{|c|c|c|c|}
\hline Constructs and survey items (Cronbach's $a=0.911$ ) & $\mathrm{N}$ & M & SD \\
\hline Exchange of information (Cronbach's $a=0.789$ ) & 365 & 4.00 & 0.76 \\
\hline Provide clear information to the patient. & 369 & 3.95 & 1.01 \\
\hline Turn to the patient in a calm and quiet tone & 369 & 3.86 & 0.95 \\
\hline Show respect to the patient as a person rather than a case. & 368 & 4.15 & 0.98 \\
\hline Pay attention to what the patient says. & 366 & 4.04 & 0.94 \\
\hline Individualization (Cronbach's $a=0.816)$ & 357 & 3.60 & 0.78 \\
\hline Show interest in what the patient feels about his status. & 366 & 3.81 & 0.92 \\
\hline Show interest in what the patient knows about his disease/prognosis. & 365 & 3.62 & 1.02 \\
\hline Show interest in what the patient wants from care. & 366 & 3.58 & 0.98 \\
\hline Show interest in what the patient expects from care in this hospital. & 365 & 3.42 & 0.97 \\
\hline Empathy (Cronbach's $a=0.747$ ) & 360 & 3.59 & 0.77 \\
\hline Understand the emotions that the patient may have. & 366 & 3.68 & 0.94 \\
\hline Check how illness affects the patient's daily life activities. & 368 & 3.70 & 0.97 \\
\hline The doctor acts as putting himself in the "patient's place". & 366 & 3.24 & 1.12 \\
\hline Inspire confidence and security when touching the patient or being nearby. & 365 & 3.75 & 1.04 \\
\hline Patient involvement (Cronbach's $a=0.796$ ) & 364 & 3.61 & 0.78 \\
\hline Give the patient enough time to ask and talk about his disease. & 368 & 3.67 & 0.96 \\
\hline Ask the patient questions that allow him to express his point of view. & 367 & 3.53 & 0.98 \\
\hline Give him encouragement and transmit optimism. & 368 & 3.85 & 0.96 \\
\hline Offer the patient an opportunity to discuss and share decision making. & 368 & 3.40 & 1.05 \\
\hline
\end{tabular}

$1=$ not at all important (minimum score), $5=$ mostly important (maximum score) 
distributed 590 surveys, 373 were returned (63\%). We excluded four disqualified surveys (either incomplete or used socially desirable answers) then we analyzed the data of (369) respondents.

\section{Data analysis techniques}

Several data analysis techniques were used to answer the proposed research questions. Data were analyzed at a 95\% confidence interval $(\alpha=0.05)$ using the SPSS 23. Descriptive statistics (RQ1), multivariate analyses of MANOVA (RQ3) and canonical correlation techniques (RQ4). In addition to cluster analysis and Chi-square analysis (RQ2). Each PCC component was assessed for reliability using Cronbach's Alpha. The coefficients of the "exchange of information", "individualization", "empathy", and "patient involvement" were $\alpha=0.79,0.82$, 0.75 , and 0.8 respectively [61].

\section{Results}

Table 1 summarizes the demographic characteristics of the participants. About 50\% of the Participants were from public hospitals. Private hospitals could be owned by the not-for-profit organization or owned by the for-profit organization but not owned by the government. About $63 \%$ of the participants got their education outside the country. Surprisingly, although $71.4 \%$ got training in communication, only $45 \%$ of the participants knew about PCC.

Most of the respondents were male doctors (74.8\%). It is worth noting that the youth two medical schools in West Bank created a better chance for females to become doctors without traveling abroad and to benefit from joining the profession of medicine. Even though, the gender gap is still common in the Palestinian hospitals ( $25 \%$ of the participants are females).

The reported perceived importance of PCC components (RQ1) On average, $48.8 \%$ considered the exchange of information with patients as "most important" or "totally important" and only $27 \%$ of doctors considered the other three PCC components as most or totally important. Previous evidence reported low levels of implementing PCC; The Agency for Healthcare Research and Quality (AHRQ) reported that only around $45 \%$ to $62 \%$ of the patient encounters "always" used the PCC approach in developed countries $[45,62]$. Palestinian doctors reported less frequent perceived importance than the previously published levels of implementing PCC. Results are shown in Table 2.

On average doctors reported high importance of "exchange of information" component $(M=4)$ than "patient involvement" components $(M=3.64)$, then "individualization" component $(M=3.6)$, and finally, the "empathy" component scored the lowest perceived importance $(M=3.59)$.

\section{Doctors differ in their views with respect to seven PCC} subjects (RQ2)

We conducted cluster analysis to find the underlying structure of relationships among the doctors based on their views about the PCC. The two-step approach for clustering (hierarchical then K-mean cluster analyses) formed three groups of doctors (Fig. 1). Further, a discriminant analysis of the outcomes was conducted, two canonical discriminant functions predicted the cluster outcomes, the model significantly discriminated the clusters, Wilks' Lambda $=0.158, p<0.01$. Function 1 explained $97.6 \%$ of the variance between clusters, the canonical correlation coefficient was 0.908 . The standardized canonical discriminant function 1 coefficients assigned high weights $(>0.2)$ to seven PCC subjects which were significant in differentiating the clusters (Table 3). Improving the perceived importance of these seven subjects could be the focus of investment in training.

Respondents' characteristics were cross-tabulated by the three clusters $(2 \times 3$ model $)$. The data was analyzed using a chi-square test of independence to look for an overall significance of the relationship between the doctor's background and the PCC cluster in which she was classified (Table 4). We used the value of standardized residuals (the difference between observed and expected value is $(>1.196$ or $<-1.196)$ ) to find which demographic attribute has the most contribution to the significance of the relationship.

Job title, age, marital status, hospital type, and familiarity with PCC were significantly associated to which cluster the doctor was located. The specialists, the aged, the married, the doctors in private hospitals, and the familiar doctors with PCC were more frequently classified by the cluster of the more perceived importance of PCC. The lack of familiarity with PCC and lack of previous training contributed most to poor views about PCC among doctors who were neither familiar with $\mathrm{PCC}$ nor trained. However, gender, experience, university of bachelor, or previous training had no significant effect $(p>0.05)$ on which PCC cluster the doctor was classified.

\section{Palestinian doctors perceive differently the importance of PCC components based on their socio-demographic characteristics or the type of hospital they work for (RQ3) Multivariate techniques were adapted because they allow for simultaneous comparisons among the variable sets and limit the probability of committing type I error in the study [63]. The approach also provides congruence between the explanatory nature of the study and the consideration of multiple possible causes on multiple ef- fects. The scores of each set of four items that represent a certain PCC component were averaged and became a mean index for that PCC component. The new four PCC scores represent the combined dependent variables}




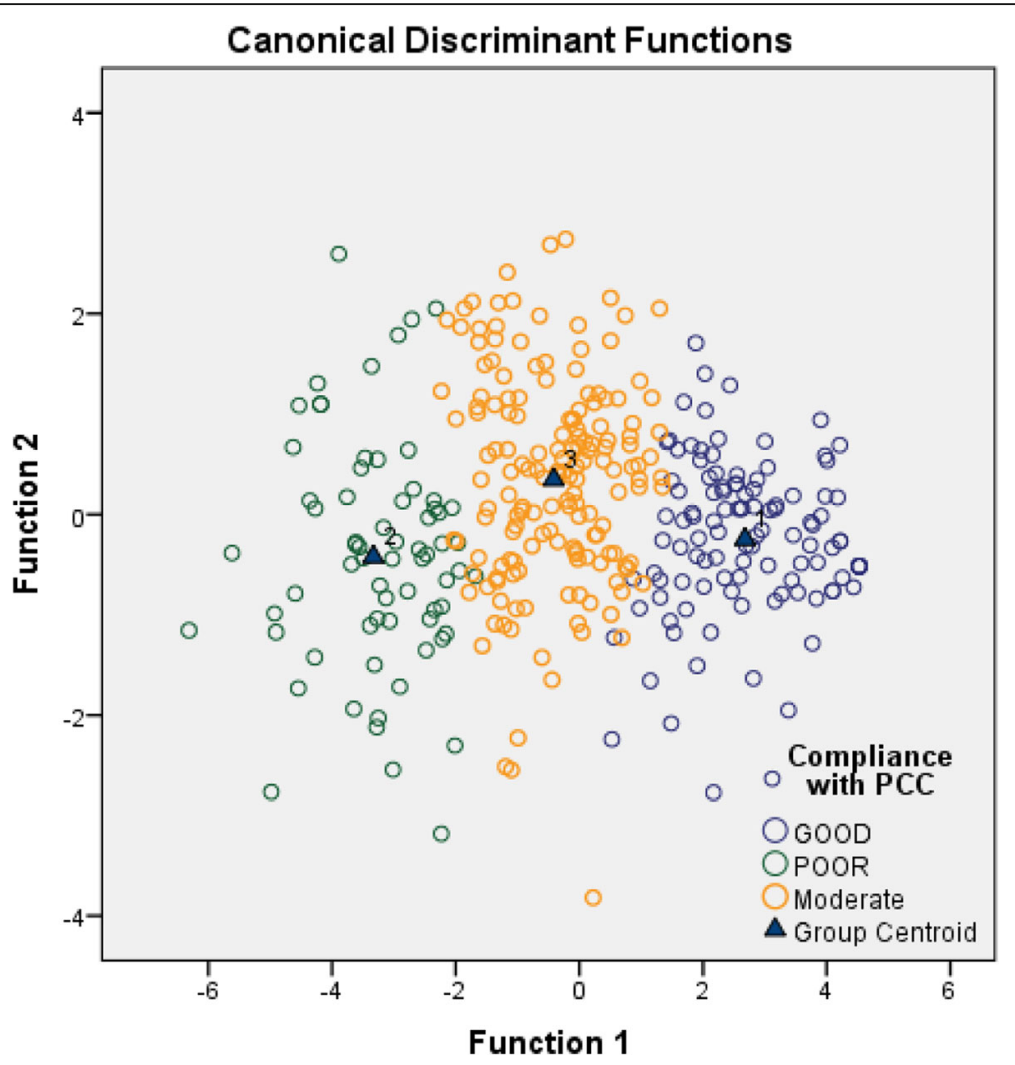

Fig. 1 Three groups of doctors based on their views on PCC

(DVs) of the study through the subsequent carried out statistical analyses. Descriptive statistics appear in Table 5. Pearson correlation between the four variables was substantial for all pairs. Empathy was the most strongly correlated with patient involvement and exchange of information $(r=0.67)$, while patient involvement was the least correlated process $(r=0.5)$ with the exchange of information.

We carried out MANOVA tests to detect whether the combined dependent variables (DVs) differ across groups of participants based on their demographic attributes (Table 6). Post hoc tests detected differences between subjects and tested for the effects of each group of respondents on each PCC component (DV). Box's M test indicated that the assumption of equality of covariance matrices was met $p>0.05$. Levene's test showed that the assumption of equality of error variance was met $p>0.05$, equality of error variance of DVs across groups was supported.

Results show that the combined dependent variables (DV) are not significantly different, in the general sense, across the three job titles (specialists, residents, and general doctors, $P>0.05$ ). However, the main effect of job title on the "individualization" component was significant (Wilk's Lambda $=0.964, \mathrm{~F}(2,343)=4.630, p=0.01$ ), the effect size of job title was 0.027. Scheffe's multiple comparisons indicate that there is a significant difference in perceived importance of "individualization" ( $p=0.018)$ between specialists and residents in favor of specialists.

Table 3 Cluster centers: seven subjects differentiate doctors based on their views on PCC

\begin{tabular}{|c|c|c|c|c|}
\hline PCC items & PCC components & $\begin{array}{l}\text { High } \\
(32.4 \%)\end{array}$ & $\begin{array}{l}\text { Moderate } \\
(47.6 \%)\end{array}$ & $\begin{array}{l}\text { Poor } \\
\text { (20\%) }\end{array}$ \\
\hline 1. Provide clear information to the patient & Exchange of information & 5 & 4 & 3 \\
\hline 2. Show respect to the patient as a person rather than a case & & 5 & 4 & 3 \\
\hline 3. Show interest in what the patient knows about his disease. & & 4 & 4 & 3 \\
\hline 4. Show interest in what the patient expects from this hospital & Individualization & 4 & 3 & 3 \\
\hline 5. Understand the emotions that the patient may have & Empathy & 5 & 4 & 3 \\
\hline 6. Give the patient enough time to ask and talk about his/her disease & Patient involvement & 4 & 4 & 3 \\
\hline 7. Offer the patient an opportunity to discuss and share decision & & 4 & 3 & 3 \\
\hline
\end{tabular}


Table 4 Descriptive associations between respondents' demographic characteristics and PCC behavioral clusters

\begin{tabular}{|c|c|c|c|c|c|c|c|c|}
\hline & & \multirow[t]{2}{*}{$\mathrm{N}$} & \multicolumn{3}{|c|}{ PCC Behavioral Clusters } & \multirow[t]{2}{*}{$x^{2}$} & \multirow{2}{*}{$\begin{array}{l}\text { Sig. }^{a} \\
p\end{array}$} & \multirow{2}{*}{$\begin{array}{l}\text { Most Contribution } \\
\text { Standardized Residual }\end{array}$} \\
\hline & & & GOOD \% & POOR \% & Moderate $\%$ & & & \\
\hline \multirow[t]{3}{*}{ Job title } & Specialist & 129 & 41.9 & 18.6 & 39.5 & 9.53 & 0.049 & Specialist X Good = 1.9 \\
\hline & Resident & 127 & 26.8 & 25.5 & 60.4 & & & \\
\hline & GP & 087 & 26.4 & 18.4 & 55.2 & & & \\
\hline \multirow[t]{2}{*}{ Gender } & Male & 258 & 33.7 & 17.4 & 48.8 & 4.67 & 0.097 & Female $X$ Poor $=1.7$ \\
\hline & Female & 085 & 28.2 & 28.2 & 43.5 & & & \\
\hline \multirow[t]{2}{*}{ Age } & $\leq 35$ years & 204 & 26.5 & 21.6 & 52.0 & 8.01 & 0.018 & $>35$ years $X$ Good $=1.8$ \\
\hline & $>35$ years & 139 & 41.0 & 18.0 & 41.0 & & & \\
\hline \multirow[t]{2}{*}{ Marital Status } & Single & 133 & 24.1 & 21.8 & 54.1 & 6.39 & 0.031 & Single $X$ Moderate $=1.1$ \\
\hline & Married & 210 & 37.6 & 19.0 & 43.3 & & & Married X Good = 1.3 \\
\hline \multirow[t]{2}{*}{ Hospital } & Public & 165 & 24.8 & 23.6 & 51.5 & 8.57 & 0.014 & Residuals are $<1.1$ \\
\hline & Private & 178 & 39.3 & 16.9 & 43.8 & & & \\
\hline \multirow[t]{2}{*}{ Experience } & $\leq 5$ years & 200 & 28.5 & 20.5 & 51.5 & 3.54 & 0.17 & $>5$ years $X$ Good $=1.2$ \\
\hline & $>5$ years & 142 & 38.0 & 19.0 & 43.0 & & & \\
\hline \multirow[t]{2}{*}{ Bachelor } & Local & 129 & 30.2 & 20.9 & 48.8 & 0.59 & 0.74 & \\
\hline & Abroad & 211 & 34.1 & 19.0 & 46.9 & & & \\
\hline \multirow[t]{2}{*}{ Training } & Untrained & 094 & 30.9 & 26.6 & 42.6 & 3.92 & 0.14 & Untrained X Poor $=1.5$ \\
\hline & Trained & 245 & 33.1 & 17.1 & 49.8 & & & \\
\hline \multirow[t]{2}{*}{ Familiar with PCC } & Unfamiliar & 185 & 28.1 & 25.4 & 46.5 & 8.02 & 0.018 & Unfamiliar X Poor = 1.6 \\
\hline & Familiar & 154 & 37.0 & 13.6 & 49.4 & & & \\
\hline
\end{tabular}

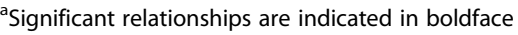

Male doctors reported the more perceived importance of PCC components than female doctors. The combined DVs were significantly different across gender groups, the effect size was 0.041 . The main effect of gender on the "individualization" component was significant $(p=0.026)$. The main effect of gender on "patient involvement" component was significant $(p=0.007)$.

Married doctors reported the more perceived importance of PCC components than unmarried doctors. The combined DVs were significantly different between married and unmarried doctors $(p=0.042)$. The main effect of marital status on "individualization", "empathy", and "patient involvement" components was significant.

Experienced doctors (with more than 5 years of experience in a hospital) reported the more perceived importance of PCC components than other doctors. The combined DVs were significantly different across the two groups. The main effect of experience on "individualization" component was significant $(p=0.005)$. The main effect of

Table 5 Descriptive statistics of four PCC components (mean indexes)

\begin{tabular}{llllll}
\hline PCC Construct & N & Min. & Max. & Mean & SD \\
\hline - Exchange of Information & 365 & 1.00 & 5.00 & 4.00 & 0.76 \\
-Individualization & 357 & 1.25 & 5.00 & 3.62 & 0.78 \\
-Empathy & 360 & 1.25 & 5.00 & 3.59 & 0.77 \\
-Patient Involvement & 364 & 1.25 & 5.00 & 3.61 & 0.78 \\
\hline
\end{tabular}

experience on "patient involvement" component was significant $(p=0.017)$.

Results show no significant differences between doctors' views on PCC components based on the place of education whether they studied in the Palestinian Medical Schools or abroad. Likewise, results show that previous training in communication skills had no significant effect, in the general sense, on the combined DVs $(P>0.05)$. However, the main effect of training on "empathy" component was significant $(p=0.023)$. The main effect of training on "patient involvement" component was also significant $(p=0.038)$.

Familiar doctors with PCC (having previous knowledge about PCC) reported more importance of PCC components than doctors who were not familiar with PCC. The combined DVs were significantly different across the two groups $(p=0.028)$. The main effect of familiarity with PCC on "individualization" component was significant $(p=0.007)$. The main effect of knowing PCC on "empathy" component was significant $(p=0.031)$. The main effect of experience on "patient involvement" component was significant $(p=0.002)$.

Finally, doctors in private hospitals reported the more perceived importance of PCC components than doctors in the public hospitals (Table 6). The combined DVs were significantly different across the two groups (Wilk's Lambda $=0.968, F(4,338)=2.75, p=0.02)$. The effect 
Table 6 The associations between the categorical variable (socio-demographic) and the PCC components (MANOVA tests)

\begin{tabular}{|c|c|c|c|c|c|}
\hline Groups & & Wilk's $\wedge$ & Test & Partial $\eta^{2}$ & In favor of \\
\hline \multirow[t]{5}{*}{ Specialists, residents, GPs } & Combined DVs & 0.964 & $F(8,674)=1.58, p=0.127$ & 0.018 & - \\
\hline & -Exchange of Information & & $F(2,343)=1.99, p=0.139$ & 0.012 & - \\
\hline & - Individualization & & $F(2,343)=4.630, \mathbf{p}=\mathbf{0 . 0 1 ^ { \mathbf { a } }}$ & 0.027 & Specialists \\
\hline & - Empathy & & $F(2,343)=1.930, p=0.14$ & 0.011 & - \\
\hline & - Involvement & & $F(2,343)=2.231, p=0.10$ & 0.013 & - \\
\hline \multirow[t]{5}{*}{ Male, female doctors } & Combined DVs & 0.959 & $F(4,338)=3.65, \mathbf{p}=\mathbf{0 . 0 0 6}$ & 0.041 & males \\
\hline & -Exchange of Information & & $F(1,343)=0.30, p=0.578$ & 0.001 & - \\
\hline & - Individualization & & $F(1,343)=4.97, \mathbf{p}=\mathbf{0 . 0 2 6}$ & 0.014 & Males \\
\hline & - Empathy & & $F(1,343)=0.080, p=0.77$ & 0.000 & - \\
\hline & - Involvement & & $F(1,343)=7.28, \mathbf{p}=\mathbf{0 . 0 0 7}$ & 0.021 & Males \\
\hline \multirow[t]{5}{*}{ Married, unmarried doctors } & Combined DVs & 0.971 & $F(4,338)=2.50, \mathbf{p}=\mathbf{0 . 0 4 2}$ & 0.029 & Married \\
\hline & -Exchange of Information & & $F(1,343)=0.80, p=0.372$ & 0.002 & - \\
\hline & - Individualization & & $F(1,343)=5.70, \mathbf{p}=\mathbf{0 . 0 1 7}$ & 0.017 & Married \\
\hline & - Empathy & & $F(1,343)=5.48, \mathbf{p}=\mathbf{0 . 0 2 0}$ & 0.016 & Married \\
\hline & - Involvement & & $F(1,343)=7.89, \mathbf{p}=\mathbf{0 . 0 0 5}$ & 0.023 & Married \\
\hline \multirow[t]{5}{*}{ Experience $>5, \leq 5$ years } & Combined DVs & 0.965 & $F(4,337)=3.08, \mathbf{p}=\mathbf{0 . 0 1 6}$ & 0.035 & Experienced \\
\hline & -Exchange of Information & & $F(1,341)=0.20, p=0.653$ & 0.001 & - \\
\hline & - Individualization & & $F(1,341)=7.90, \mathbf{p}=\mathbf{0 . 0 0 5}$ & 0.023 & Experienced \\
\hline & - Empathy & & $F(1,341)=1.68, p=0.195$ & 0.005 & - \\
\hline & - Involvement & & $F(1,341)=6.01, \mathbf{p}=\mathbf{0 . 0 1 5}$ & 0.017 & Experienced \\
\hline \multirow[t]{5}{*}{ Local education, abroad } & Combined DVs & 0.989 & $F(4,335)=0.950, p=0.43$ & 0.011 & - \\
\hline & -Exchange of Information & & $F(1,338)=0.34, p=0.558$ & 0.001 & - \\
\hline & - Individualization & & $F(1,341)=0.67, p=0.414$ & 0.002 & - \\
\hline & - Empathy & & $F(1,341)=0.07, p=0.796$ & 0.000 & - \\
\hline & - Involvement & & $F(1,341)=2.50, p=0.112$ & 0.007 & - \\
\hline \multirow[t]{5}{*}{ Trained, untrained doctors } & Combined DVs & 0.979 & $F(4,334)=1.80, p=0.127$ & 0.021 & - \\
\hline & -Exchange of Information & & $F(1,337)=0.16, p=0.694$ & 0.000 & - \\
\hline & - Individualization & & $F(1,337)=1.75, p=0.178$ & 0.005 & - \\
\hline & - Empathy & & $F(1,337)=5.25, \mathbf{p}=\mathbf{0 . 0 2 3}$ & 0.015 & Trained \\
\hline & - Involvement & & $F(1,337)=4.33, \mathbf{p}=\mathbf{0 . 0 3 8}$ & 0.013 & Trained \\
\hline \multirow[t]{5}{*}{ Familiarity with (PCC) } & Combined DVs & 0.968 & $F(4,334)=2.75, \mathbf{p}=\mathbf{0 . 0 2 8}$ & 0.032 & Familiar \\
\hline & -Exchange of Information & & $F(1,337)=2.39, p=0.125$ & 0.007 & - \\
\hline & - Individualization & & $F(1,337)=7.27, \mathbf{p}=\mathbf{0 . 0 0 7}$ & 0.021 & Familiar \\
\hline & - Empathy & & $F(1,337)=4.67, \mathbf{p}=\mathbf{0 . 0 3 1}$ & 0.014 & Familiar \\
\hline & - Involvement & & $F(1,337)=9.98, \mathbf{p}=\mathbf{0 . 0 0 2}$ & 0.029 & Familiar \\
\hline \multirow[t]{5}{*}{ Public, private hospital } & Combined DVs & 0.968 & $F(4,338)=2.75, \mathbf{p}=\mathbf{0 . 0 2 8}$ & 0.037 & Private \\
\hline & -Exchange of Information & & $F(1,343)=11.8, \mathbf{p}=\mathbf{0 . 0 3 4}$ & 0.034 & Private \\
\hline & - Individualization & & $F(1,343)=6.09, \mathbf{p}=\mathbf{0 . 0 1 4}$ & 0.018 & Private \\
\hline & - Empathy & & $F(1,343)=3.49, p=0.063$ & 0.010 & - \\
\hline & - Involvement & & $F(1,343)=6.18, \mathbf{p}=\mathbf{0 . 0 1 3}$ & 0.018 & Private \\
\hline
\end{tabular}

${ }^{a}$ Significant effects are indicated in boldface

size was 0.037 . The main effect of hospital setting on the "exchange of information" component was significant (F $(1,343)=11.8, p=0.034)$. The effect size was 0.034 . The main effect of hospital setting on "individualization" component was significant $(\mathrm{F}(1,343)=6.09, p=0.014)$, the effect size was 0.018 . The main effect of hospital 
types on "patient involvement" component was significant $(F(1,343)=6.18, p=0.013)$, the effect size was 0.018. But there was no significant effect of hospital type on "empathy" component $(p=0.063)$.

\section{The relation between the presence of contextual factors and doctors' views on PCC (RQ4)}

The projected eight contextual attributes were measured on a five-point Likert scale ranging from "totally disagree" to "totally agree" and coded from one to five respectively (Table 7).

We conducted a canonical correlation analysis (CCA) using the set of eight contextual factors as a predictor variable set of the four PCC components as the criterion variable set (given in Table 5). The purpose was to answer the study question whether doctors' working conditions are predictive of the perceived importance of PCC components by evaluating the multivariate relationship between the two variable sets. The four PCC components of interest are the dependent variable set (DVs).

The analysis yielded four functions with squared canonical correlations $\left(\mathrm{Rc}^{2}\right)$ of $.213, .047, .011$ and .009 respectively. Collectively, the full CCA model $(N=331)$ was statistically significant, with a Wilk's $\lambda$ of (0.73), F $(32,1178)=3.21, p<0.001$ and explained $(1-\lambda=27 \%)$ of shared variance between the two variable sets. Thus, the $r^{2}$ type effect size was 0.27 [63]. The dimension reduction analysis allowed for hierarchal tests for significance and revealed that the full CCA model (Functions 1 to 4$)$ was statistically significant $F(32,1178)=3.2$, $p<0.001$. Functions 2 to 4,3 to 4 , and function 4 tests did not explain a statistically significant amount $(p>0.05)$ of shared variance between the variable sets. Therefore, we considered the effect of function 1 to identify the contributing variable as it captured most of the shared variance and not to interpret the effect of other functions as they only explained less than $5 \%$ of the variance.

Table 8 presents the standardized canonical function coefficients and structure coefficients for Function 1. Structure coefficients are used to decide what variables are contributing to this relationship. Looking at the
Table 8 The standardized canonical function coefficients

\begin{tabular}{llll}
\hline Criterion Variables (DVs) & \multicolumn{3}{l}{ Function 1} \\
\hline Exchange of information & -0.454 & -0.851 & 72.4 \\
Individualization & -0.107 & -0.778 & 60.5 \\
Empathy & -0.215 & -0.819 & 67.1 \\
Shared decision & -0.413 & -0.855 & 78.3 \\
Predictor Variables (IVs) & & & \\
Administration support. & -0.040 & +0.182 & 3.30 \\
Workload. & +0.040 & +0.172 & 3.00 \\
Nurses' cooperation. & -0.349 & -0.475 & 22.5 \\
Level of job satisfaction & +0.087 & -0.358 & 12.8 \\
Level of job Interest. & -0.729 & -0.696 & 48.4 \\
Doctor's formal style. & +0.574 & +0.530 & 28.1 \\
Patients tend hide information. & -0.266 & -0.169 & 2.90 \\
Low level of health literacy. & +0.148 & +0.050 & 0.25 \\
\hline
\end{tabular}

coefficients, all the PCC components have a contribution as supported by the large squared structure coefficients $\left(\mathrm{r}_{\mathrm{s}}^{2}\right)$, which represents the shared variance between the observed PCC scores and the variate created from the observed variable's set.

However, the four predictor variables job interest, doctor's style, nurses' cooperation, and the patient's tendency to hide information were the primary contributors to the predictor variate (Table 9). The doctor's style predictor was negatively related to all the PCC components which support the theoretically expected relation, the more formal the doctor interviews his patients, the less he considers PCC as important. The other three predictors were positively related.

The results of the regression bivariate analysis supported the analysis of standardized canonical function coefficients. Beta weights reflected the relative contribution of each predictor to the PCC processes [63]. The relationship was significant to all the four predictors (with high canonical function coefficients) of the four PCC components. Two exceptions involve no significance, the Patient's

Table 7 Scores and descriptive statistics of the proposed eight contextual factors

\begin{tabular}{|c|c|c|c|}
\hline Contextual barrier $^{\mathrm{a}}$ & $\mathrm{N}$ & Mean & SD \\
\hline Hospital culture does not support effective medical interview. & 367 & 3.07 & 1.10 \\
\hline I am overloaded, and I don't have enough time for a good interview. & 368 & 3.24 & 1.11 \\
\hline Nurses cooperate positively. & 364 & 2.78 & 0.99 \\
\hline I feel satisfied with my work in this hospital (N). & 362 & 2.69 & 0.99 \\
\hline I find my job as interesting $(\mathrm{N})$. & 367 & 2.11 & 0.93 \\
\hline I prefer to be formal rather than warm and friendly. & 369 & 2.83 & 1.14 \\
\hline Patients tend to give less information due to social consequences. & 366 & 3.48 & 0.94 \\
\hline Most patients are not aware of their health status or their disease. & 365 & 3.44 & 1.07 \\
\hline
\end{tabular}

${ }^{\mathrm{a}}(1)=$ strongly disagree, (5) = strongly agree. $\mathrm{N}$, negatively worded item 
Table 9 Regression analysis and causality relationships

\begin{tabular}{|c|c|c|c|c|c|c|c|c|}
\hline \multirow[t]{2}{*}{ Significant Predictor Variables } & \multicolumn{2}{|c|}{ Exchange of Information } & \multicolumn{2}{|c|}{ Individualization } & \multicolumn{2}{|c|}{ Empathy } & \multicolumn{2}{|c|}{ Involvement } \\
\hline & $\beta$ & $p$ & $\beta$ & $p$ & $\beta$ & $p$ & $\beta$ & $p$ \\
\hline Level of job interest & 0.34 & $<0.001$ & 0.24 & $<0.001$ & 0.21 & $<0.001$ & 0.27 & $<0.001$ \\
\hline Doctor's formal style & -0.23 & $<0.001$ & -0.25 & $<0.001$ & -0.22 & $<0.001$ & -0.21 & $<0.001$ \\
\hline Nurses' cooperation & 0.06 & 0.252 & 0.13 & 0.02 & 0.18 & 0.001 & 0.19 & 0.001 \\
\hline Patient's tendency to hide information & 0.12 & 0.026 & 0.05 & 0.33 & 0.11 & 0.047 & 0.10 & 0.080 \\
\hline
\end{tabular}

tendency to hide information with "individualization" component and the nurses' cooperation with the "exchange of information" component.

PCC behaviors were significantly associated with the adopted personal style of the doctors. Doctors who adopted a formal style rather than a warm, friendly style were negatively correlated with PCC components. The four PCC components were significantly negatively correlated $(p<0.001)$. Pearson coefficients were $-0.2,-0.24$, $-0.20,-0.19$ respectively.

\section{Discussion}

The first research objective of this study was to assess the doctors' perceived importance of PCC among hospital doctors. The remarkable finding was the prevalence of unfamiliarity with PCC (55\% of the Palestinian doctors never knew about PCC). These results were observed by other researchers in developing countries [50], where it is not uncommon that the patients' voice is ignored by care provider [64].

The perceived importance of PCC among Palestinian doctors was significantly different between doctors in private and doctors in public hospitals in favor of doctors in private hospitals. Doctors in public hospitals were more frequently classified in poor and moderate clusters of doctors based on their perceived importance $(23.6 \%$ and $51.5 \%$ respectively). MANOVA tests supported the same result. Previous evidence also supported our results as the state of public hospitals in Palestine overcrowded and suffer understaffing. Professionals work in crisis-mode and perceive medical interview as time-consuming $[26,27]$. Others found that, in developing countries, private hospitals are competing and induced to provide better services than public ones [65].

Doctors, based on their views on PCC, were classified into three groups (1) the good cluster, highly recognize the importance of PCC (2) the poor cluster, and (3) the moderate cluster. Doctors were significantly differentiated into clusters by seven PCC subjects, investment decisions in training should stress these seven PCC subjects. Meanwhile, a remarkable result indicated that the lack of training or lack of familiarity with PCC was statistically associated with the poor perception of the importance of PCC. Previous evidence showed that nearly all educational and training interventions had improved interpersonal skills among doctors [7]. Results show that the specialists, the aged, and the married doctors are more frequently in the cluster of good views. This study didn't investigate the motives behind good views on PCC among these doctors, it may be hypothesized that good performers devoted self-developed social skills and individual professionalism to meet the patients' psychosocial expectations.

In the general sense, the socio-demographic factors: significant differences exist across the groups of gender, marital status, experience, and familiarity with PCC in favor of males, married, experienced, and familiar with PCC doctors respectively (Table 6). Male doctors have the advantage of the more perceived importance of PCC than female doctors. This result is explained by the common culture among Palestinians and the gender gap for closer communication, further research could be useful.

Training in communication, in the overall sense, was not significantly associated with the more perceived importance of PCC. Yet, training is significantly associated with "empathy" and "patient involvement" components. Training should assist doctors to become more informative, empathic and mindful of moving their role as characterized by the authority to one that has the goals of the partnership, solidarity, and collaboration [46]. Our results are consistent with previous evidence which show significant differences between doctors based on personal differences or patient differences [49, 66-68].

Doctors who adopted formal style during the medical interview were less likely to exchange information with patients than doctors approaching their patients in a warm and friendly style. Further, a doctor's formal style was negatively correlated to all PCC components. Literature suggests a consistent finding is that doctors with a warm and friendly style to be more effective in emotional and cognitive care [48].

The preliminary model of canonical correlation analysis discussed in this study provides insights to both hospital managers and policy makers who might use the results to improve implementing PCC. Improving PCC performance will enhance service quality in the hospital environment in Palestine. The model identified four significant predictable factors as perceived by the doctors that have significant effects on the four PCC processes of interest (Table 9). This is important because doctors' 
perceptions have behavioral implications on their performance. Investments in managing these factors will have positive influences on patients as they will receive better care of the often-neglected psychosocial dimensions of hospital services.

Since all the four predictors had a significant association with the perceived importance of PCC components, managers might base PCC enhancement strategies based on the parameters of the model. The standardized $\beta$ s provide straightforward answers to the targeted improvements. Addressing the job interest issue $(\beta=0.34 \mathrm{SD})$ will deliver the greatest improvement in the perceived importance of the "exchange of information" component. To formulate a strategy of four items to improve the perceived importance of "empathy" component by 1SD, it requires an increase of 0.21SD of job interest, an increase of 0.18SD of nurse collaboration, and an increase of perception among doctors that patients may hide relevant information due to social consequences of $0.11 \mathrm{SD}$. In addition to decreasing the level of formality in doctor's style by 0.18SD.

Findings showed patient-related factors that influence the doctor's views. The perception on the doctor's side about his patients can't be ignored [53]. Surprisingly, the perception of low levels of health literacy had no significant influence on the doctor's PCC behaviors. Additional research is needed to investigate health literacy in Palestine [52]. Second, the patients' tendency to hide relevant information due to felt social consequences had promoted doctors to more PCC intention, increased perceived importance of "exchange of information" $(\beta=0.12)$, increased "empathy" $(\beta=0.11)$, and increased "patient involvement" $(\beta=0.10)$ Doctors who perceived this tendency reacted positively to improve patient engagement.

\section{Conclusion}

While attention to improving the quality of services provided in Palestinian hospitals is growing, the problems of the health care delivery system are reported with increasing frequency in the public media. This work is the first research to investigate the consultation between doctor and patient among Palestinian doctors, little is known about the topic. The study identified factors that contribute to the doctors' performance and highlighted the challenges of implementing PCC in a developing and unstable context, namely, Palestine.

While previous literature focused on how to implement PCC, this study investigated the vital components of the healthcare system that underpin effective PCC behaviors. This study introduced a prior knowledge about personal, professional and organizational aspects and their relationships with better views on PCC among Palestinian doctors in hospitals. It is of significance as it comes at a time when the Palestinian Ministry of Health is adopting a family practice model. Doctors are requested to have better attitudes towards PCC, this will help the public authorities to effectively adopt the family practice model as a strategy to manage the overcrowded state of work of the Palestinian hospitals.

Results highlighted gaps between public and private hospitals, managers of public hospitals can benchmark the private hospitals to enhance attitudes towards PCC. Results also suggest that both types of hospitals have room for improving their doctors' interpersonal skills. Hospital managers might base PCC enhancement strategies on the parameters of the canonical correlation model and pay more attention for managing the identified predictors of PCC behaviors. The study is limited to doctors' views on PCC and generates the question of patients' perceptions and views to identify their informative and PCC needs within the Palestinian context.

\section{Additional file}

Additional file 1: Palestinian Doctors' Views on Patient-Centered Care in Hospitals. (DOCX $24 \mathrm{~kb}$ )

\section{Abbreviations \\ AHRQ: Agency for Healthcare Research and Quality; ANOVA: Analysis of Variance; CCA: Canonical Correlation Analysis; $\mathrm{MoH}$ : Palestinian Ministry of Health; PCC: Patient Centered Care; PPRQ: Provider Patient Relationship Questionnaire; RQ: Research Question; SDRS: Socially Desiarable Response Set}

\section{Acknowledgments}

We acknowledge the Palestinian Ministry of Health for their cooperation. We extend our gratitude to doctors in public and non-public hospitals who devoted time to complete the surveys. Special thanks go to Tânia Moreira for her valuable comments on data analysis.

Availability of data and materials

The used datasets during the study and the analysis are available from the corresponding author.

Authors' contributions

WS and MS were responsible for the surveys carried out in 2016. MS explained the purpose of the study to the participants during the distribution of the questionnaire. WS and JC were responsible for data analysis. All authors contributed to the conception, the data interpretation, drafting the article and the final approval of the article.

\section{Ethics approval and consent to participate}

Ethical approval was obtained from the General Directorate of Medical Education at the Palestinian Ministry of Health. The surveys were anonymously distributed, and all participants were informed verbally that their participation was voluntary. The need for written consent is deemed unnecessary according to national regulations.

Consent for publication

Not applicable.

Competing interests

The authors declare that they have no competing interests.

\section{Publisher's Note}

Springer Nature remains neutral with regard to jurisdictional claims in published maps and institutional affiliations. 


\section{Author details}

'School of Administrative Sciences, PPU-Palestine \& NIPE-Portugal, Hebron, Palestine. ${ }^{2}$ School of Medicine, Al-Quds University, Al Quds, Palestine. ${ }^{3}$ INESC TEC, Porto, Portugal.

\section{Received: 10 April 2018 Accepted: 27 September 2018} Published online: 11 October 2018

\section{References}

1. Beck RS, Daughtridge R, Sloane PD. Physician-patient communication in the primary care office: a systematic review. J Am Board Fam Pract Am Board Family Med. 2002;15:25-38.

2. DeVoe JE, Wallace LS, Fryer GE Jr. Measuring patients' perceptions of communication with healthcare providers: do differences in demographic and socioeconomic characteristics matter? Heal Expect Wiley Online Library. 2009; 12:70-80

3. Fuertes JN, Toporovsky A, Reyes M, Osborne JB. The physician-patient working alliance: Theory, research, and future possibilities. Patient Educ Couns. 2017;100(4):610-15.

4. Hibbard $\mathrm{JH}$. Patient activation and the use of information to support informed health decisions. Patient Educ. Couns. Elsevier. 2016.

5. Joyce BL, Steenbergh T, Scher E. Use of the Kalamazoo essential elements communication checklist (adapted) in an institutional interpersonal and communication skills curriculum. J Grad Med Educ. 2010:2:165-9 The Accreditation Council for Graduate Medical Education Suite 2000, 515 North State Street, Chicago, IL 60654.

6. Kim SS, Kaplowitz S, Johnston MV. The effects of physician empathy on patient satisfaction and compliance. Eval Health Prof Sage Publications. 2004;27:237-51.

7. Perron NJ, Sommer J, Louis-Simonet M, Nendaz M. Teaching communication skills: beyond wishful thinking. Swiss med. Wkly. 2015;145: w14064 EMH SWISS MEDICAL PUBLISHERS LTD FARNSBURGERSTR 8, CH4132 MUTTENZ, SWITZERLAND.

8. Rathert C, Wyrwich MD, Boren SA. Patient-centered care and outcomes: a systematic review of the literature. Med Care Res Rev Sage Publications Sage CA: Los Angeles, CA. 2013;70:351-79.

9. Reynolds A. Patient-centered care. Radiol Technol Am Soc Radiol Tech. 2009;81:133-47.

10. Singh S, Evans NT, Williams M, Sezginis N, Baryeh NAK. Influences of sociodemographic factors and health utilization factors on patient-centered provider communication. Health Commun. 2018;33(7):917-23.

11. Oates J, Weston WW, Jordan J. The impact of patient-centered care on outcomes. Fam Pr. 2000:49:796-804

12. Lewis CP, Newell JN. Improving tuberculosis care in low income countries-a qualitative study of patients' understanding of "patient support" in Nepal. BMC public health. BioMed Central. 2009;9:190.

13. RN SSPD. Effects of patient-centered care on patient outcomes: an evaluation. Res Theory Nurs Pract Springer Publishing Company. 2008;22:24.

14. Robinson JH, Callister LC, Berry JA, Dearing KA. Patient-centered care and adherence: definitions and applications to improve outcomes. J Am Acad Nurse Pract Wiley Online Library. 2008:20:600-7.

15. Fenton JJ, Kravitz RL, Jerant A, Paterniti DA, Bang H, Williams D, et al. Promoting patient-centered counseling to reduce use of low-value diagnostic tests: a randomized clinical trial. JAMA intern. Med. American Medical Association. 2016;176:191-7.

16. Greene SM, Tuzzio L, Cherkin D. A framework for making patient-centered care front and center. Perm J. 2012;16(3):49.

17. Berghout M, van Exel J, Leensvaart L, Cramm JM. Healthcare professionals' views on patient-centered care in hospitals. BMC health Serv. Res. BioMed Central. 2015:15:385

18. Gremigni P, Casu G, Sommaruga M. Dealing with patients in healthcare: a self-assessment tool. Patient Educ. Couns. Elsevier. 2016:99(6):1046-53.

19. Stewart M. Towards a global definition of patient centred care: the patient should be the judge of patient centred care. BMJ. Br Med J BMJ Publishing Group. 2001;322:444.

20. Donabedian A. An introduction to quality assurance in health care: Oxford University Press; 2002.

21. Manary MP, Boulding W, Staelin R, Glickman SW. The patient experience and health outcomes. N Engl J Med Mass Medical Soc. 2013:368:201-3.

22. Sultan WIM, Crispim J. Measuring the efficiency of Palestinian public hospitals during 2010-2015: an application of a two-stage DEA method. BMC health Serv. Res. BioMed Central. 2018;18:381.
23. Giacaman R, Abdul-Rahim HF, Wick L. Health sector reform in the occupied Palestinian territories (OPT): targeting the forest or the trees? Health Policy Plan Oxford Univ Press. 2003;18:59-67.

24. Haj-Yahia MM, Sousa C, Alnabilsy R, Elias H. The influence of Palestinian physicians' patriarchal ideology and exposure to family violence on their beliefs about wife beating. J Fam Violence Springer. 2015;30:263-76.

25. Haj-Yahia MM. Attitudes of Palestinian physicians toward wife abuse their definitions, perceptions of causes, and perceptions of appropriate interventions. Violence Against Women Sage Publications. 2013;19:376-99.

26. Hamdan M, Saleem AA. Assessment of patient safety culture in Palestinian public hospitals. Int J Qual Heal care. 2013;25:167-75.

27. Kitaneh $M$, Hamdan M. Workplace violence against physicians and nurses in Palestinian public hospitals: a cross-sectional study. BMC health Serv. Res. BioMed Central. 2012;12:1.

28. Mu'taz MD, Alrimawi I, Saifan AR, Batiha A-M. Hand hygiene knowledge, practices and attitudes among nurses and physicians. Health (Irvine. Calif). Scientific Research Publishing. 2016;8:456.

29. Rashed A, Hamdan M. Physicians' and Nurses' Perceptions of and Attitudes toward Incident Reporting in Palestinian Hospitals. J. Patient Safety. http// dx. doi. org/https://doi.org/10.1097/PTS. 2015;218.

30. Hamdan M. Measuring safety culture in Palestinian neonatal intensive care units using the safety attitudes questionnaire. J Crit Care Elsevier. 2013;28:886-e7.

31. Saleh S, Alameddine M, Mourad Y, Natafai N. Quality of care in primary health care settings in the eastern Mediterranean region: a systematic review of the literature. Int J Qual Heal Care [Internet]. 2015;27:79-88 Available from: https://doi.org/10.1093/intahc/mzu103.

32. Shahawy S, Diamond M. Attitudes of Palestinian medical students on the geopolitical barriers to accessing hospitals for clinical training: a qualitative study. Confl. Health. BioMed Central. 2016;10:1

33. Mataria A, Khatib R, Donaldson C, Bossert T, Hunter DJ, Alsayed F, et al. The health-care system: an assessment and reform agenda. Lancet Elsevier. 2009:373:1207-17.

34. WHO. Health conditions in the occupied Palestinian territory, including East Jerusalem, and in the occupied Syrian Golan. Provisional Agenda item. 2015;20

35. Bloom G, Standing $H$, Lloyd R. Markets, information asymmetry and health care: towards new social contracts. Soc Sci Med. 2008;66:2076-87.

36. Health M of. Annual Statistical Report 2015 [Internet]. 2016. Available from: https://www.site.moh.ps/index/Books/BookType/2/Language/ar. [cited 2016 Apr 18]

37. Tutton $E$, Seers $K$, Langstaff $D$. Professional nursing culture on a trauma unit: experiences of patients and staff. J Adv Nurs Wiley Online Library. 2008;61: 145-53.

38. Kitson A, Marshall A, Bassett K, Zeitz K. What are the core elements of patientcentred care? A narrative review and synthesis of the literature from health policy, medicine and nursing. J. Adv. Nurs. Wiley Online Library. 2013;69:4-15.

39. Lee H, Vlaev I, King D, Mayer E, Darzi A, Dolan P. Subjective well-being and the measurement of quality in healthcare. Soc Sci Med. 2013;99:27-34.

40. Elwyn G, Frosch D, Thomson R, Joseph-Williams N, Lloyd A, Kinnersley P, et al. Shared decision making: a model for clinical practice. J Gen Intern Med Springer. 2012;27:1361-7.

41. Hojat M. Empathy and patient outcomes. Empathy Heal. Prof. Educ. Patient Care Springer. 2016:189-201.

42. Sommaruga M, Casu G, Giaquinto F, Gremigni P. Self-perceived provision of patient centered care by healthcare professionals: the role of emotional intelligence and general self-efficacy. Patient Educ Couns Elsevier. 2017; 100:974-80.

43. Borkowski N. Organizational behavior in health care. Jones \& Bartlett Publishers. 2015.

44. Fagerlind H, Kettis $\AA$, Glimelius B, Ring L. Barriers against psychosocial communication: oncologists' perceptions. J Clin Oncol American Society of Clinical Oncology. 2013;31(30):3815-22

45. Schwartz F, Lowe M, Sinclair L. Communication in healthcare: considerations and strategies for successful consumer and team dialogue. Hypothesis. 2010;8.

46. Epstein RM, Street RL. The values and value of patient-centered care. Ann Fam Med Annals Family Med. 2011;9:100-3.

47. Cushing A. History of the doctor-patient relationship. Clin Commun Med John Wiley \& Sons. 2015;3.

48. Di Blasi Z, Harkness E, Ernst E, Georgiou A, Kleijnen J. Influence of context effects on health outcomes: a systematic review. Lancet. Elsevier. 2001;357: 757-62. 
49. Hall JA, Roter DL. Do patients talk differently to male and female physicians? A meta-analytic review Patient Educ Couns Elsevier. 2002;48:217-24.

50. M'hamdi Hl, van Voorst SF, Pinxten W, Hilhorst MT, Steegers EAP. Barriers in the uptake and delivery of preconception care: exploring the views of care providers. Matern Child Health J Springer; 2017;21:21-28.

51. Grady A, Carey M, Bryant J, Sanson-Fisher R, Hobden BA. Systematic review of patient-practitioner communication interventions involving treatment decisions. Patient Educ. Couns. Elsevier. 2016.

52. Osborne RH, Beauchamp A, Batterham R. Health literacy: a concept with potential to greatly impact the infectious diseases field. Int J Infect Dis Elsevier. 2016:43:101-2.

53. Saultz A, Saultz JW. Measuring outcomes: lessons from the world of public education. Ann Fam Med Annals Family Med. 2017:15:71-6.

54. Glock S, Kovacs C. Educational psychology: using insights from implicit attitude measures. Educ Psychol Rev Springer. 2013;25:503-22.

55. Symons AB, Swanson A, MCGuigan D, Orrange S. Akl EA. a tool for selfassessment of communication skills and professionalism in residents. BMC med. Educ. BioMed Central Ltd. 2009;9:1.

56. Amsalu E, Boru B, Getahun F, Tulu B. Attitudes of nurses and physicians towards nurse-physician collaboration in Northwest Ethiopia: a hospital based cross-sectional study. BMC Nurs. BioMed Central Ltd. 2014;13:37.

57. Nguyen T, Bauman GS, Watling C, Hahn K. Oncology physician attitudes toward patient and family centered care. Int J Radiat Oncol Biol Phys Elsevier. 2015;93:E361.

58. Epling JW, Morley CP, Ploutz-Snyder R. Family physician attitudes in managing obesity: a cross-sectional survey study. BMC res. Notes. BioMed Central Ltd. 2011;4:473.

59. Jabr NH. Physicians' attitudes towards knowledge transfer and sharing Compet Rev An Int Bus J. 2007;17:248-60.

60. Hays RD, Hayashi T, Stewart AL. A five-item measure of socially desirable response set. Educ Psychol Meas Sage Publications. 1989;49:629-36.

61. Nunally JC, Bernstein IH. Psychometric theory. New York: McGraw-Hill; 1978.

62. Kelley E, Moy E, Stryer D, Burstin H, Clancy C. The national healthcare quality and disparities reports: an overview. Med Care LWW. 2005;43:I-3.

63. Sherry A, Henson RK. Conducting and interpreting canonical correlation analysis in personality research: a user-friendly primer. J Pers Assess Taylor \& Francis. 2005:84:37-48.

64. Andaleeb SS. Service quality perceptions and patient satisfaction: a study of hospitals in a developing country. Soc Sci Med Elsevier. 2001:52:1359-70.

65. Andaleeb SS. Service quality in public and private hospitals in urban Bangladesh: a comparative study. Health Policy (New. York). Elsevier. 2000; 53:25-37.

66. Bertakis KD. The influence of gender on the doctor-patient interaction. Patient Educ. Couns. Elsevier. 2009:76:356-60.

67. Duberstein P, Meldrum S, Fiscella K, Shields CG, Epstein RM. Influences on patients' ratings of physicians: physicians demographics and personality. Patient Educ. Couns. Elsevier. 2007:65:270-4.

68. Kalra S, Sridhar GR, Balhara YPS, Sahay RK, Bantwal G, Baruah MP, et al. National recommendations: psychosocial management of diabetes in India. Indian J Endocrinol Metab Medknow Publications. 2013;17:376.

\section{Ready to submit your research? Choose BMC and benefit from:}

- fast, convenient online submission

- thorough peer review by experienced researchers in your field

- rapid publication on acceptance

- support for research data, including large and complex data types

- gold Open Access which fosters wider collaboration and increased citations

- maximum visibility for your research: over $100 \mathrm{M}$ website views per year

At $\mathrm{BMC}$, research is always in progress.

Learn more biomedcentral.com/submissions 